\title{
Niğde Ömer Halisdemir Üniversitesi Öğrencilerinin Kültürlararası Duyarlılıkları Üzerine Bir Araştırma
}

DOI: $10.26466 /$ opus.643764

\author{
Duygu Ünalan * \\ * Dr. Öğr. Üyesi, Niğde Ömer Halisdemir Üniversitesi, Merkez/Niğde/Türkiye \\ E-Posta: duyguunalan85@gmail.com ORCID: 0000-0002-7420-2006
}

\section{$\ddot{O} z$}

Son iki yüz yllda insanlık tarihinde yaşanan teknolojik gelişmeler ve küreselleşme ile birlikte dünya üzerinde sınırlar ortadan kalkmış ve farklı kültürlerden bireylerin etkileşim zorunluluğu artmıştır. Özellikle eğitim amaçl yaşanan öğrenci değiş̧imleri, başka bir ülkede eğitim görme olanakları bireylerin farklı bir kültür coğrafyasında uzun süreli yaşaması gerekliliğini de beraberinde getirmiştir. Böylece kültürlerarası karşılaşmalar artmış ve kültürlerarası iletişim yeteneği önemli hale gelmiştir. Kültürlerarası iletişim yeteneğinin geliştirilebilmesi için bireylerde öncelikle kültürlerarası duyarlılığın gelişmesi gerekmektedir. Bu bağlamda bu çalışmada Niğde Ömer Halisdemir Üniversitesi öğrencilerinin kültürlerarası duyarlllık düzeylerinin belirlenmesi amaçlanmıştır. Çalışmada Chen ve Starosta'nın kültürlerarası duyarlılık kavramsallaştırması temel alınmıştır. 392 öğrenciye Chen ve Stratosta tarafından geliştirilen "Kültürlerarası Duyarlılık Ölçĕ̆i" uygulanmış, elde edilen veriler SPSS 24.0 programında sayısallaştırılmıştır. Çalışmada Frekans Analizi, Keşfedici Faktör Analizi, Korelasyon Analizi ve Bağımsız Örneklem T-Testi yapılmıştır. Dört faktörün ortaya çıktı̆̆ı analizler sonucunda Niğde Ömer Halisdemir Üniversitesi'nde öğrenim gören öğrencilerin cinsiyetlerine göre kültürlerarası duyarlılıklarının anlamlı bir farklllı gösterdiği görülmüştür.

Anahtar Kelimeler: Kültür, Kültürlerarası Iletişim, Kültürlerarası iletişim yeterliği, Kültürlararası duyarlılık, Kültürlerarası duyarlılık ölçeği 


\title{
A Research on Intercultural Sensitivity of Nigde Ömer Halisdemir University Students
}

\begin{abstract}
With the technological developments and globalization in the history of humanity in the last two hundred years, the borders on the world disappeared and the interaction necessity of individuals from different cultures increased. In particular, the exchange of students for educational purposes and the opportunity to study in another country have brought along the necessity of individuals to live in a different cultural geography for a long time. Thus, intercultural encounters increased and intercultural communication skills became important. In order to develop intercultural communication skills, first of all, intercultural sensitivity should be developed. In this context, the aim of this study was to determine the intercultural sensitivity level of Niğde Ömer Halisdemir University students. The study was based on the conceptualization of intercultural sensitivity of Chen and Stratos. Intercultural Sensitivity Scale developed by Chen and Stratosta was applied to 392 students and the data obtained were digitized in SPSS 24.0 program. Frequency Analysis, Exploratory Factor Analysis, Correlation Analysis and Independent Sample T-Test were performed. As a result of the analysis that revealed four factors, it was seen that the intercultural sensitivity of the students studying at Niğde Ömer Halisdemir University showed a significant difference.
\end{abstract}

Keywords: Culture, Intercultural communication, Intercultural communication competence, Intercultural sensitivity, Intercultural sensitivity scale. 


\section{Giriş}

20. yüzyılda insanlık bilimsel ve teknolojik gelişmeler açısından önceki yüzyıllarda tanık olunmayan bir ilerleme kaydetmiştir. Bu gelişmeler, sosyal ve kültürel bağlamda insan yaşamını olumlu etkilemiştir. Ancak yeni iletişim teknolojilerinde görülen gelişmeler yanında uluslararası şirketler ve bazı devletler, sınırsız siyasal ve ekonomik amaçlarını bu yüzyılda gerçekleştirmişlerdir. Emperyalizm, dünyayı küresel bütün haline getirmiş, devletler ve kültürler arasında asimetrik ilişkiler başlamış, takas ve karşılıklı bağımlılığa dayalı ekonomik ilişkiler yaygınlaşmıştır. Bu egemenlik ilişkisi her ne kadar olumsuz sonuçlar getirse de eşitlik ve farklılığın tanındığı koşullarda, farklılıkların karşılaşmalarını mümkün kılan ilişkilerin kurulmasına da ortam sağlamıştır (Kartarı, 2014, s.26-27). Dolayısıyla yüzyıllardır birlikte yaşayan ancak yakın çevresi ile etkileşim kuran insan toplulukları küreselleşme ile birlikte sını ötesi ilişkiler kurmaya başlamışlardır.

1490 ' da feodal beyliklerin merkantalizm düşüncesi ile çevre ülke ve kıtalara düzenledikleri seferlerle başlayan ve asıl gelişimini 1990'lı yıllardan itibaren yaşayan küreselleşme olgusu; dünyayı ekonomik, siyasal, sosyokültürel ve teknolojik alanda hızlı bir değişime sürüklemiştir. Küreselleşme, uluslararası ilişkiler ve kültürlerarası etkileşimleri yoğunlaştırarak ekonomik, siyasal ve sosyokültürel tüm kural ve maddi-manevi değerlerin standartlaşmasını sağlamıştır. Ulusal sınırları aşarak, sınırları belirsizleştirmiş, finans ve kapital başta olmak üzere her şeyin zaman ve mekân engeli tanımaksızın dünya çapında dolaşımını olanaklı hale getirmiştir. Bu yönleri ile küreselleşme, dinamik ve ideolojik bir süreç olarak varlığını sürdürmektedir (Saran, 2013, s.443).

Sosyal ve ekonomik gelişmeler, küreselleşme ve uluslararasılaşma, farklı kültürlerden bireylerin etkileşimlerinde iletişim yeterliliğinin önemini arttırmıştır. Dolayısıyla bireyler, farklı kültürlerle karşılaşmalarında kültürlerarası duyarlılığa daha fazla ihtiyaç duymaya başlamışlardır. Kültürlerarası duyarlılık ihtiyacının büyümesi kültürlerarası karşılaşmalarda açıkça görülmektedir. Küreselleşme, uluslararasılaşma ve iletişimde ilerlemeler, kültürlerarası iletişim ve etkileşim fırsatını arttırmıştır. Kültürlerarası iletişim ve etkileşim için bireylere daha büyük fırsatlar sağlayan gelişmeler göz önüne alındığında kültürlerarası duyarlılık, sosyal ve iletişimsel bir yetenek olarak büyük bir rol 
üstlenmiştir (Fritz vd. 1999'dan aktaran, Fritz vd., 2002: 165; Tamam, 2010, s.174).

Başka bir kültürde etkili olabilmek için, insanlar diğer kültürlere ilgi duymalı, kültürel farklılıkları fark edebilecek kadar duyarlı olmalı ve diğer kültürlerden olan insanlara saygı göstergesi olarak davranışlarında değişiklik yapmaya istekli olmalıdırlar (Bhawuk ve Brislin, 1992, s.416). Bu bağlamda "kültürlerarası duyarlılık" terimi, kültürel farklılıkları ayırt edebilme ve deneyimleme yeteneğini ifade etmektedir (Hammer vd., 2003, s.422). Bu noktadan hareketle bu çalışmada, Niğde Ömer Halisdemir Üniversitesinde öğrenim gören öğrencilerin kültürlerarası duyarlılık düzeyleri nedir? sorusuna yanıt aranmaktadır. Çalışmanın amacı, Niğde Ömer Halisdemir Üniversitesinde öğrenim gören öğrencilerin kültürlerarası duyarlılık düzeylerini ortaya koymaktır. Çalışmada 392 öğrenciye kültürlerarası duyarlılık ölçeği uygulanmıştır.

\section{Kültürlerarası İletişim ve Kültürlerarası Duyarlılık}

Kültür, yapılandırılmış insan gruplarının, çoğu zaman kendileri farkında olmadan yaşamlarını düzenleyen, herkesçe kabul edilmiş kurallardır. Bu kurallar biyolojik kalıtımla kazanılmamakta, sonradan öğrenilmektedir. Toplum üyelerinin gündelik davranış, düşünce ve duygu kalıplarını bu kurallar belirlemektedir. Bu nedenle insan etkinlikleri, düşünceleri ve duyguları kültür aracılığıyla edinilmekte ve kültürden etkilenmektedir (Haviland, vd. 2008, s.69).

Kültür, kültürel antropoloji ve kültürlerarası psikolojide bir ulus ya da dünya bölgesi gibi tanınabilir büyük grupların kolektif yaşam deneyimlerini ifade etmektedir. Yıllar içinde kavram, diğerlerinin yanı sıra cinsiyet, fiziksel yetenek ya da engellilik, coğrafi bölgeler boyunca yerli etnik ya da irksal grupların alt kültürlerini içerecek biçimde genişlemiştir. Kültürlerarası iletişim de söz konusu farklı kültürler ve alt kültürlerden olan bireyler arasındaki iletişim ve etkileşime odaklanmaktadır (Kim, 2005, s.555-556).

İletişim; bireylerin birbirlerinin ortamlarındaki nesneler, olaylar, olgularla ilgili değişmeleri haber veren; bunlara ilişkin deneyimlerini birbirlerine aktaran, aynı olgular, nesneler, sorunlar karşısında benzer yaşam deneyimlerinden kaynaklanan, benzer duygular taşıyıp bunları birbirine ifade eden insan- 
ların oluşturdukları toplum yaşamı içinde gerçekleştirilen tutum, yargı, düşünce ve duygu aktarımıdır (Oskay, 2007, s.9). Söz konusu duygu, düşünce ya da tutum aktarımı farklı kültürden bireyler arasında gerçekleştiğinde kültürlerarası iletişim kavramı karşımıza çıkmaktadır. Farklı kültürlerden insanlar arasındaki yüz yüze etkileşimi konu edinen kültürlerarası iletişim, farklı kültürlerden olan kaynak ve alıcı arasındaki sembol paylaşımında ortaya çıkabilecek iletişim farklılıklarını anlamaya çalışmaktadır (Jant, 2004, s.39).

İnsanlık tarihi boyunca bireyler, daha iyi bir yaşam alanı bulmak, ticaret yapmak ya da din başta olmak üzere belirli düşünceleri yaymak için seyahat etmişlerdir. Yaşam ortamlarından farklı bir yere gidince, farklı yaşam koşullarında yetişmiş, bir başka deyişle farklı kültürlerden bireylerle karşılaşmışlardır. İletişim ve ulaşım teknolojilerinde sağlanan gelişmelerle dünya McLuhan'ın deyimiyle "küresel bir köy" haline gelmiştir. Özellikle son elli yılda yaşanan gelişmeler, dünyanın giderek küçülmesine neden olmuş, dolayısıyla hiçbir ulus ya da kültür diğerleriyle ilişkisini keserek yaşayamaz duruma gelmiştir. Yeni teknoloji ve haberleşme sistemleri, dünya nüfusunun artması, dünya ekonomik merkezlerinin değişmesi, sosyo kültürel ve ekonomik göçlerin artması farklı kültürlerden bireyler arasındaki iletişimi de yoğunlaştırmıştır (Kartarı, 2001, s.9). Bütün bu gelişmeler kültürlerarası iletişim yeterliliği ve onun tamamlayıcısı ve pekiştirici olan kültürlerarası duyarlılığın önemini arttırmış ve onu vazgeçilmez duruma getirmiştir (Bekiroğlu and Balcı, 2014, s.433).

Kültürlerarası iletişim yeterliliğinin gelişmesi, etkileşime katılan farklı kültürlerden bireylerin kültürel farklılıkları tanıması, onlara saygı duyması ve hoşgörüyle karşılaması, böylece farklı kültürel ortamlarda etkin iletişim kurabilmesini sağlamaktadır. Söz konusu yeterliliğin gelişmesi üç aşamada gerçekleşmektedir ve ilk aşamayı kültürlerarası duyarlılık bileşeni oluşturmaktadır. İkinci aşama kültürlerarası uyanıklık, üçüncü aşama ise kültürlerarası becerikliliktir. Bu süreçler birbirini izlemekte ve önceki aşama tamamlanmadan diğerine geçilmemektedir (Kartarı, 2001, s.211). Dolayısıyla kültürlerarası duyarlılığın gelişimi diğer aşamaların gelişiminde bir ön koşuldur.

Bu çalışmada Chen ve Starosta'nın kültürlerarası duyarlılık kavramsallaştırması temel alınmaktadır. Chen ve Starosta'ya (1997, s.5) göre kültürlerarası duyarlılık; etkileşim durumunun bilişsel, duygusal ve davranışsal yönü ile ilgili olmakla birlikte temel olarak duygusal alanla ilgilenmektedir. Bununla 
birlikte bilişsel düzeye karşılık gelen kültürlerarası farkındalık, duygusal düzeye karşılık gelen kültürlerarası duyarlılığın temelidir ve ikisi sırayla kültürlerarası yeterliliğe ulaştırmaktadır. Bu kavramlar yakın ilişkili olmakla birlikte, ayrı kavramlardır. Dolayısıyla kültürlerarası duyarlılık, bireyin kültürlerarası iletişimde uygun ve etkili davranışları destekleyen kültürel farklılıkları anlama ve takdir etmeye yönelik olumlu bir duygu geliştirme yeteneği olarak tanımlanabilir. Kültürlerarası duyarlılığa sahip bireyler, kültürlerarası farklılıkları anlamak, takdir etmek, kabul etmek ve kültürlerarası etkileşimlerden olumlu sonuçlar almak için kendilerini motive etmeye istekli olmalıdirlar.

\section{Kültürlerarası Duyarlılığın Ölçümü}

Bu çalışmada Chen ve Starosta'nın "Kültürlerarası Duyarlılık Ölçeği” temel alınmaktadır. Ancak konuya ilişkin litaretürdeki diğer çalışmalara değinmek yerinde olacaktır. Kültürlerarası duyarlılığa ilişkin geliştirilen ilk modellerden biri, Bennett' in insanların kültürel farklılıkları nasıl yorumladıklarını anlamaya yönelik olarak geliştirdiği Kültürlerarası Duyarlılık Gelişim Modeli'dir (Development Model of Intercultural Sensitivity-DMIS) (Hammer vd., 2003, s.423). Bennett' in modeli etnomerkezcilikten etnorelativizme doğru giden bir süreçten oluşmaktadır. Bu sürecin ilk aşamasında farklılığı reddetme, farklılığa karşı olma ve farklılıkları en aza indirme aşamaları yer almaktadır. Etnorelativizm boyutunda ise farklılığın kabul edilmesi, farklılığa uyum sağlanması ve bütünleşme aşamaları bulunmaktadır.

Genel olarak söylemek gerekirse, etnomerkezci yönelimler kültürel farklılıklardan kaçınmak, onların varlığını inkar etmek, önemini azaltmak ya da onlara karşı savunma geliştirmek olarak görülebilir. Etnorelativist yönelimler ise daha çok kültürel farklılıkların önemini kabul etme, onlara adapte olma ve bütün kültürel kimliğe entegre olma olarak açıklanabilir (Bennett, 1998, s.26-31).

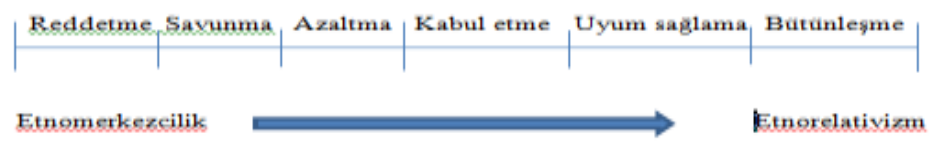

Şekil 1. Bennett'in Kültürlerarası Duyarlılık Gelişim Modeli (Bennett, 1998, s.26). 
Kültürlerarası duyarlılık düzeyinin ölçümüne ilişkin geliştirilen bir başka model ise "Kültürlerarası Gelişim Envanteri"dir (Intercultural Development Inventory- IDI). Bu ölçek, Kültürlerarası Duyarlılık Gelişim Modeli'nde yer alan kültürlerarası farklılıklara ilişkin yönelimleri ölçmek amacıyla geliştirilmiştir. Çalışma sonucunda kültürlerarası yeterliliğin ölçülmesi için 10'u demografik özelliklere ilişkin olmak üzere 50 madde içeren bir kağıt-kalem formu ortaya çıkmıştır (Hammer vd., 2003, s.421).

Bhawuk ve Brislin tarafından geliştirilen "Kültürlerarası Duyarlılık Envanteri'nde (Intercultural Sensitivity Inventory-ICSI) ise kültürlerarası duyarlılık, insanların bireyci ve kolektivist kültürlerdeki yönelimleri, farklı kültürlerden bireylerle olan etkileşimlerindeki açı fikirlilikleri ve diğer kültürlerin normlarına uygun davranış kalıplarıyla ilgili esneklikleri üzerinden incelenmiştir. Hawaii, Doğu-Batı merkezindeki uluslararası şirketlerde kariyer hedefleyen MBA programındaki lisansüstü öğrenciler arasında uygulanan ölçek 46 maddeden oluşmaktadır (Bhawuk and Brislin, 1992, s.413).

$\mathrm{Bu}$ çalışmanın temel aldığı Chen ve Starosta tarafından geliştirilen Kültürlerarası Duyarlılık Ölçeği (Intercultural Sensitivity Scale- ISS), ilk aşamada 73 madde olarak tasarlanmıştır ve her bir madde için 5'li Likert ölçeği kullanılmıştır (Chen ve Starosta, 2000: , s.5). Bu maddeler, yazarların kültürlerarası duyarlılığın ölçümünde bireylerde olması gerektiğini düşündükleri altı özelliğe göre tasarlanmıştır. Bunlar; ösaygı, öz izleme, açık görüşlülük, empati ve önyargısızlıktır. Bu kavramlardan yola çıkarak kültürlerarası duyarlılık düzeyi yüksek bireylerin kültürlerarası iletişimde yabancılaşma, hayal kırıklığı ve stres ile başa çıkabilen; uyuşmazlık durumunda davranışlarını değiştirebilme, farklı iletişim durumlarına adapte olabilme yeteneğine sahip, farklı düşüncelere açık, empati kurabilen ve önyargılardan arınmış bireyler olmaları gerektiğini söylemek mümkündür (Chen ve Starosta, 1997, s.7-10)

Chen ve Starosta (2000, s.5-8), İletişim Fakültesi'nde öğrenim gören 168 birinci sınıf öğrencisinin katılımıyla yaptıkları ilk çalışma sonucunda faktör analizi ile ölçeği 44 maddeye indirmişlerdir. İkinci çalışmada ise Kültülerarası Duyarlılık Ölçeği'nin ilgili ölçekler ile eşzamanlı geçerliliğini test etmeyi amaçlamışlar ve çalışma sonunda ölçeği 24 madde olarak yeniden tasarlamışlardır. Bu 24 madde, kültürlerarası duyarlılığa ilişkin 5 faktörün açılımıdır: Bunlar; "etkileşimde sorumluluk", " kültürel farklara saygı", "etkileşimde kendine güvenme" ve "etkileşimde dikkatli olma"dır. 
Kültürlerarası Duyarlılık Ölçeği temel alınarak yapılan çalışmalardan biri Fritz, Möllenberg ve Chen tarafından 2002 yılında yapılmıştır. Yazarlar, "Measuring Intercultural Sensitivty in Different Cultural Contexts" başlıklı çalışmaların Almanya Mannheim Üniversitesi'nde öğrenim gören 541 işletme yönetimi öğrencisinin katılımıyla gerçekleştirmişlerdir. Daha sonra örneklem sayısını Chen ve Starosta'nın örneklem sayısı ile eşleşecek biçimde rastgele seçimle 400'e indirmişlerdir. Doğrulayıcı faktör analizinin yapıldığı çalışmada, Almanya örneğinde ölçeğin temel yapısı doğrulanmıştır (Fritz vd., 2002, s.165-168).

Fritz ve arkadaşları, 2005 yılında Amerika ve Almanya örneğinde çalışmalarını yinelemişlerdir. Çalışmaya 188 Amerikan, 179 Alman öğrenci katılmıştır. Çalışma sonucunda modelin geçerliliğinin sadece Almanya örneğinde yapılan çalışmada doğrulandığı, ancak bu çalışmada ise aynı sonucun ortaya çıkmadığı görülmüştür. Yazarlar, Chen ve Starosta'nın modelinin külttürlerarası geçerliğinin bu çalışma için şüpheli gözüktügünü ve geleceğe yönelik çalışmaların daha çok inceleme gerektirdiğini belirtmişlerdir (Fritz vd., 2005, s.53-55).

Pendek ve arkadaşlarının 2009 yılında yaptıkları "Intercultural Communication Competence: A Study About the Intercultural Sensitivity of University Students Based on Their Education and International Experiences" başlıklı çalışmalarında üniversite öğrencilerinin eğitimlerine ve uluslararası deneyimlerine dayalı olarak kültürlerarası duyarlılıklarını incelemişlerdir. Araştırmanın örneklemi, İzmir Ekonomi Üniversitesi İktisadi, Sosyal ve İdari Bilimler Fakültesi ile Dokuz Eylül Üniversitesi Deniz İşletmeciliği Yüksekokulu ve Yönetimi öğrencilerinden seçilen 266 kişiden oluşmaktadır, ancak ankete 200 kişi katılmıştır. Araştırmada, uluslararası etkileşimlerdeki sorumluluk düzeylerini geliştirmek için öğrencilerin farklı kültürlere saygı duydukları sonucuna varılmıştır (Pendek vd. 2009).

2010 yılında Bulduk, Tosun ve Ardıç tarafından yapılan bir diğer çalışma ise "Measurement Properties of Turkish Intercultural Sensitivity Scala Among Nursing Students" başlığını taşımaktadır. Araştırmacılar, Kültürlerarası Duyarlılık Ölçeği'nin Türkçe formunun iç tutarlılığını, güvenilirliğini ve faktöriyel yapısını hemşirelik öğrencilerinin örneğinde incelemişlerdir. Öncelikle Türkçe ölçeğin psikometrik uygunluğu 148 hemşirelik öğrencisi üzerinde değerlendirilmiş, iki hafta sonra ise 32 öğrenci ile test-tekrar test ger- 
çekleştirilmiş ve testin tutarlılığı yeterli düzeyde bulunmuştur. Yapılan psikometrik analizlerle Kültürlerarası Duyarlılık Ölçeğinin geçerlilik ve güvenilirliği desteklenmiştir (Bulduk vd., 2011, s.25).

"Examining Chen and Starosta's Model of Intercultural Sensitivity in a Multiracial Collectivistic Country" başlıklı çalışmasında Ezhar Tamam, kültürlerarası duyarlılık ölçeğinin üniversite öğrencileri örneğinde Malezya kültüründe uygulanabilir olup olmadığını incelemiştir. Ölçek, çok kültürlü bir kamu üniversitesinde öğrenim gören ve rastlantısal olarak belirlenmiş 447 öğrenciye uygulanmıştır. Çalışma sonucunda 5 faktörden oluşan modelin Malezya'nın kültürel bağlamına tam olarak uymadığı belirlenmiştir. Bunun yerine Chen ve Starosta'nın ölçeğindeki 21 maddeyi kapsayan 3 faktör ortaya koyulmuştur. Bunlar: "etkileşimde dikkatli olma ve sayg1", "etkileşimde açıklık" ve "etkileşimde güven" faktörleridir (Tamam, 2010, s.173).

2013 yılında Awang-Rozaimie ve arkadaşları tarafından yurtdışında yaşayan ve öğrenim gören Malezyalı öğrenciler örneğinde yapılan araştırmada, kültürlerarası duyarlılığın Malezyalı öğrencilerin yurtdışında okurken ya da yaşarken kültürlerarası etkileşimlerindeki etkisinin ne olduğu üzerinde durulmuştur. Çalışmada 500 öğrenciyle e-mail yoluyla iletişime geçilmiş 248 dönüş alınmıştır. Bu dönüşlerin ise 187'si analize alınmıştır. Çalışma sonucunda kültürlerarası duyarlılık düzeyinin yüksekliğinin yurtdışındaki Malezyalı öğrencilerin külttürlerarası uyumunu kısmen kolaylaştırdığı bulgusuna ulaşılmıştır (Rozaimie vd., 2013, s. 693-697).

2014 yılında Bekiroğlu ve Balcı tarafından "Looking for the Clues of Sensitivity of Intercultural Communication: "A Survey on the Sample of Communication Faculty Students" adlı çalışmada ise Selçuk Üniversitesi İletişim Fakültesi öğrencilerinin kültürlerarası iletişim duyarlılığı incelenmiştir. 302 öğrenciye yüzyüze anket uygulanmıştır. Çalışma sonucunda Chen ve Starosa'nın ölçeğindeki 5 faktörün tümüyle yinelenmediği, 4 faktör grubunun ortaya çıktığı saptanmıştır. Bununla birlikte Erasmus değişim programından yararlanma isteği, farklı ülkelerin medyasını takip etme sıklığı, sosyal medyada farklı kültürlerden bireylerle iletişim kurma sıklığı, farklı kültüre sahip bir ülkede yaşama isteği ve yabancı dil bilme düzeyine göre kültürlerarası duyarlılık düzeylerinin anlamlı bir biçimde farklılaştığı belirlenmiştir (Bekiroğlu ve Balc1, 2014, s. 429). 


\section{Araştırmanın Yöntemi}

Niğde Ömer Halisdemir Üniversitesi'nde öğrenim gören öğrencilerin kültürlerarası duyarlılıklarını ölçmeyi amaçlayan bu çalışmada Chen ve Starosta'nın Kültürlerarası Duyarlılık Ölçeği uygulanmıştır. Ölçek, 5 faktör ve bunlara karşılık gelen 24 maddeden oluşmaktadır. Katılımcların ifadelere yönelik yantları için "5=Tamamen Katılıyorum", "4=Katıliyorum", "3=Kararstzım", "2=Katılmıyorum", "1=Hiç Katılmıyorum" 5'li Likert tipi ölçek esas alınmıştır. Beş faktör içinde "etkileşimde sorumluluk", katılımcıların kültürlerarası iletişimde katılıma yönelik duyguları ile ilgilidir. 1, 11, 13, 21, 22, 23, 24. maddeler, "etkileşimde sorumluluk" faktörünün kapsamındadır. "Kültürel farklılıklara saygı" faktörü temelde katılımcıların farklı kültür ve fikirlere ilişkin yönelimlerini ya da toleransların irdelemektedir. Bu faktörü; 2, 7, 8, 16, 18, 20. maddeler temsil etmektedir. "Etkileşimde kendine güvenme", katılımcıların kültürlerarası ortamda kendilerinden ne kadar emin olduklarını sorgulamaktadır. 3, 4, 5, 6, 10. maddeler bu faktör içerisinde yer almaktadır. Dördüncü faktör olan "etkileşimden hoşlanma", farklı kültürlerden insanlarla iletişim kurmaya karşı pozitif ya da negatif tepki göstermeyle ilgilidir. "Etkileşimden hoşlanma" faktörü 9, 12 ve 15. maddeler üzerinden ele alınmaktadır. Son olarak, "etkileşimde dikkatli olma" faktörü ise katılımcların kültürlerarası etkileşimde neler olduğunu anlamaya yönelik çabalarını irdelemeye yöneliktir. Bu son faktör, ölçek içinde 14, 17 ve 19. maddelerde ele alınmaktadır (Chen ve Starosta, 2000, s. 14). Chen ve Starosta'nın (2000) ölçekle ilgili olarak belirttiği üzere; $2,4,7,9,12,15,18,20$ ve 22. maddeler ters kodlanmıştır. Dolayısıyla bu olumsuz ifadeler, okumada olumlu olarak anlamlandırılmalıdir.

İlgili envanter, Niğde Ömer Halisdemir Üniversitesi etik kurulunun 28.03.2018 tarihli, 02 sayılı izni ile 2017-2018 bahar yarıyılında Niğde Ömer Halisdemir Üniversitesi'nde öğrenim gören 392 öğrenciye uygulanmıştır. Dolayısıyla çalışmanın evrenini Niğde Ömer Halisdemir Üniversitesi öğrencileri oluşturmaktadır. 392 kişilik örneklem grubu ise farklı evrenler için kabul edilebilir örneklem büyüklükleri tablosu ${ }^{1}$ baz alınarak belirlenmiştir. Niğde Ömer Halisdemir Üniversitesi'nde 2018-2019 öğretim yılında 28.681

\footnotetext{
${ }^{1}$ Gürbüz, S. ve Şahin, F. (2016). Sosyal Bilimlerde Araştırma Yöntemleri. Ankara: Seçkin Yayınları, s.132.
} 
öğrenci öğrenim görmüştür. ${ }^{2}$ Bu rakam dikkate alındığında ilgili tabloda \%95 güvenilirlik oranı asgari örneklem sayısının 379 olması gerektiği belirtilmektedir. Dolayısıyla çalışmaya katılan kişi sayısı \%95 güvenilirlik oranını karşılamaktadır. Alan araştırması, 1-30 Nisan 2018 tarihleri arasında gerçekleştirilmiştir. Elde edilen veriler, SPSS 24.0 istatistik programı kullanılarak sayısallaştırılmıştır. Verilerin analizinde sırasıyla; anket sorularını cevaplayanların demografik özelliklerini belirlemek amacıyla Frekans Analizi; kültürlerarası iletişim duyarlılık düzeyi faktörlerini ortaya koymak amacıyla Keşfedici Faktör Analizi yapılmıştır. Kültürlerarası iletişim duyarlılık düzeyi faktörleri arasındaki ilişkinin yönünü belirlemek amacıyla Korelasyon Analizi, kültürlerarası iletişim duyarlılık düzeyi ile cinsiyet arasındaki ilişkiyi belirlemek için Bağımsız Örneklem T-testi yapılmıştır.

\section{Bulgular ve Yorumlar}

Bu başlık altında katılımcıların demografik özelliklerine ilişkin bulgular, kültürlerarası iletişim duyarlılık düzeyi faktörleri, faktörler arası korelasyon analizi ve Bağımsız Örneklem T-testi sonuçlarına yer verilmiştir.

\section{Katılımcıların Sosyo-Demografik Özellikleri}

Çalışmaya toplam 392 öğrenci katılmıştır. Katılımcılara demografik özellikleri açısından cinsiyetleri ve uyrukları sorulmuştur.

Tablo 1. Katılımcıların demografik özelliklerine ilişkin bulgular

\begin{tabular}{lllll}
\hline & & Türk & Yabancı Uyruklu & Toplam \\
\hline \multirow{2}{*}{ Cinsiyet } & Kadın & 158 & 37 & 195 \\
& Erkek & 148 & 49 & 197 \\
& Toplam & 306 & 86 & 392 \\
\hline
\end{tabular}

${ }^{2}$ http://www.ohu.edu.tr/oidb/sayfa/ogrenci-sayilari 


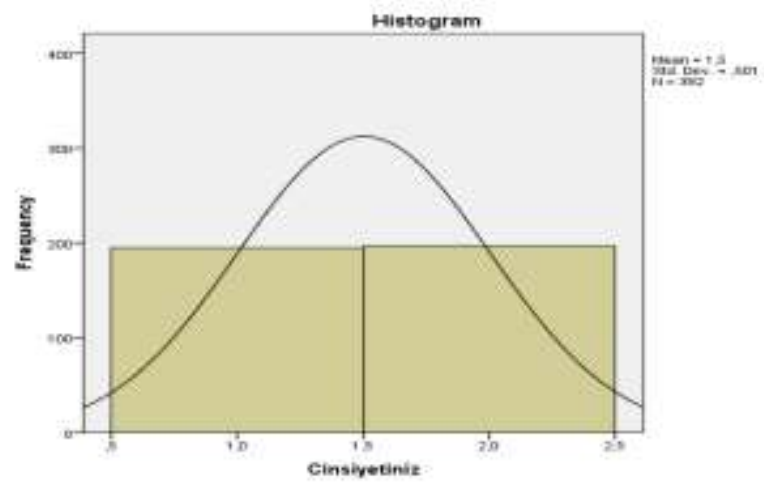

Şekil 2. Cinsiyet Değiş̧keni Çarpıklık, Basıklık Ĕ̆risi

Katılımcıların demografik özelliklerinin dağllımına bakıldığında toplam 195 kadın ve 197 erkek anketi cevaplamıştır. Kadınların 158'i Türk, 37'si yabancı uyrukludur. Erkeklerin ise 148'i Türk 49'u yabancı uyrukludur. Dolayısıyla toplamda 306 Türk, 86 yabancı uyruklu öğrenci ankete katılmıştır. Elde edilen oranlar ve çarpıklık, basıklık eğrisi, katılımcıların cinsiyetleri açısından karşılaştırma yapmaya elverişli olduğunu göstermektedir.

Kültürlerarası İletişim Duyarhlık Düzeyi Faktörleri ve Faktörler Arası Korelasyon

Niğde Ömer Halisdemir Üniversitesi öğrencilerinin kültürlerarası duyarlılıklarını ölçmek amacıyla Chen ve Starosta tarafından geliştirilmiş 24 maddelik Kültürlerarası Duyarlılık Ölçeği uygulanmıştır. Ölçeğin yapısal geçerliliğini tespit etmek amaciyla temel bileşenler (principal component) analizi ve "varimaks" eksen dördürmesi tekniği kullanılarak Keşfedici Faktör Analizi (KFA) yapılmıştır. KFA sonucunda Kaiser-Meyer-Olkin (KMO) örneklem yeterlilik değerinin 0.84 olduğu ve örneklem büyüklüğünün faktör analizi için yeterli olduğu tespit edilmiştir.

Tablo 2.KMO ve Bertlett's Test Tablosu

Kaiser-Meyer-Olkin Measure of Sampling Adequacy

Bartlett's Test of Sphericity

Approx. Chi-Square

Sig. 
Bartlett's küresellik testinin anlamlı olmas1 [ $\left.\mathrm{x}^{2(276)=2358,064} \mathrm{p}<0,05\right]$ maddeler arası korelasyon ilişkisinin faktör analizi için uygun olduğunu göstermektedir. KFA'da özdeğerlerin (eigenvalues) 1 'den büyük olması durumunda faktörlerin oluşması sağlanmıştır. KFA analizi sonucunda öncelikle altı faktörlü bir sonuç elde edilmiştir. İlk faktör analizi sonucunda on iki maddenin çapraz yüklenme eğilimi gösterdiği görülmüş, bu nedenle bu maddeler ölçekten ç1karılmıştır. Yeniden yapılan KFA sonucunda 12 maddelik ölçeğin dört faktörlü bir yapıda olduğu görülmüştür.

Faktörler, toplam varyansın \%54,898'ini açıklamaktadır. Maddelerin faktör yüklerinin 0.5 'in üzerinde olduğu tespit edilmiştir. 12 maddelik ölçeğin faktör yükleri tablo 3 'te gösterilmiştir. Faktör yükü $0.3^{\prime}$ ün altında olan değerler tabloda gösterilmemiştir. Bu sonuçlar, ölçeğin 12 maddeden oluşan dört faktörlü yapısının geçerliliğine işaret etmektedir.

"Etkileşimden Hoşlanma" faktörünü oluşturan maddelere bakıldığında bireylerin farklı kültürlerden bireylerle etkileşim kurarken rahat ve cesur oldukları, kendilerini işe yarar hissettikleri, farklı kültürlerden bireylerle bir araya gelmekten hoşlandıkları anlaşılmaktadır. Bu faktör toplam varyansın $\% 16,262$ 'sini açıklamaktadır. Faktörün güvenilirliği ise Cronbach's $\alpha$ $=.658^{\prime}$ dir.

Tablo 3. Kültürlerarası Duyarlılık Ölçeği KFA Sonuçları

\begin{tabular}{|c|c|c|c|c|}
\hline Madde & $\begin{array}{c}\text { Etkileşimden } \\
\text { Hoşlanma }\end{array}$ & $\begin{array}{c}\text { Kültürel } \\
\text { Farklılıklara } \\
\text { Sayg1 }\end{array}$ & $\begin{array}{c}\text { Etkileşimde } \\
\text { Kendine } \\
\text { Güvenme }\end{array}$ & $\begin{array}{l}\text { Etkileşimde } \\
\text { Sorumluluk }\end{array}$ \\
\hline KDÖ12 & ,796 & & & \\
\hline KDÖ15 & 790 & & & \\
\hline KDÖ9 & 577 & & & \\
\hline KDÖ22 &, 532 & & & \\
\hline KDÖ16 & & 813 & & \\
\hline KDÖ16 & & ,757 & & \\
\hline KDÖ8 & & ,713 & & \\
\hline KDÖ6 & & & 872 & \\
\hline KDÖ5 & & &, 838 & \\
\hline KDÖ11 & & & & 741 \\
\hline KDÖ21 & & & & 641 \\
\hline KDÖ19 & & & &, 553 \\
\hline Özdeğerler (Eigenvalues) & 2,114 & 2,055 & 1,568 & 1,400 \\
\hline Açıklanan Varyans Yüzdesi \% & 16,262 & 15,811 & 12,060 & 10,765 \\
\hline Toplam Açıklanan Varyans & 54,898 & & & \\
\hline
\end{tabular}


İkinci faktör olan "Kültürel Farklılıklara Sayg" toplam varyansın $\% 15,811$ 'ini açıklamaktadır ve güvenilirliği Cronbach's $\alpha=.732$ ' dir. Bu faktörü oluşturan maddeler, insanların farklı kültürlerden bireylerin davranışlarına saygı duyduklarına, farklı kültürlerden bireylerle etkileşim halinde iken mümkün olduğunca çok bilgi edinmeye çalıştıklarına ve farklı kültürlerden bireylerin değerlerine saygı duyduklarına işaret etmektedir.

"Etkileşimde Kendine Güvenme" faktörü ise toplam varyansın \%12,060'ını açıklamaktadır. Güvenilirliği Cronbach's $\alpha=.690$ olan faktörü oluşturan maddeler farklı kültürlerden bireylerle etkileşim kurarken söze nasıl başlayacaklarını bildiklerine işaret etmektedir.

Son faktör olan "Etkileşimde Sorumluluk" faktörü ise toplam varyansın $\% 10,765$ 'ini açıklamaktadır. Cornbach's $\alpha=.410$ 'dur. Bu faktörü oluşturan maddeler, bireylerin farklı kültürlerden insanlara ilişkin izlenim oluşturmada ön yargılı olmadıklarına, onların davranışlarına karşı duyarlı olduklarına ve onlara olumlu tepkiler verdiklerine işaret etmektedir.

Tablo 4. Kültürlerarası İletişim Duyarlılık Düzeyi Faktörleri Arasındaki Korelasyon Analizi Bulgulari (Pearson r)

\begin{tabular}{|c|c|c|c|c|c|}
\hline & & $\begin{array}{l}\text { Etkileşimden } \\
\text { Hoşlanma }\end{array}$ & $\begin{array}{l}\text { Kültürel } \\
\text { Farklılıklara } \\
\text { Sayg1 }\end{array}$ & $\begin{array}{l}\text { Etkileşimde } \\
\text { Kendine } \\
\text { Güvenme }\end{array}$ & $\begin{array}{l}\text { Etkileşimde } \\
\text { Sorumluluk }\end{array}$ \\
\hline \multirow{3}{*}{$\begin{array}{l}\text { Etkileşimden } \\
\text { Hoşlanma }\end{array}$} & $r$ & 1 &,$- 404^{* *}$ &,$- 201^{* *}$ &,$- 148^{* *}$ \\
\hline & $p$ & & , 000 & ,000 & ,003 \\
\hline & $\mathbf{N}$ & 392 & 392 & 392 & 392 \\
\hline \multirow{3}{*}{$\begin{array}{l}\text { Kültürel } \\
\text { Farklılıklara Saygı }\end{array}$} & $r$ &,$- 404^{* *}$ & 1 & $105^{*}$ & $193^{* *}$ \\
\hline & $p$ &, 000 & & ,039 & ,000 \\
\hline & $\mathbf{N}$ & 392 & 392 & 392 & 392 \\
\hline \multirow{3}{*}{$\begin{array}{l}\text { Etkileşimde } \\
\text { Kendine Güvenme }\end{array}$} & $\mathbf{r}$ &,$- 201^{* *}$ & , $105^{*}$ & 1 & $132^{*}$ \\
\hline & $p$ & 000 & 039 & & 009 \\
\hline & $\mathbf{N}$ & 392 & 392 & 392 & 392 \\
\hline \multirow{3}{*}{$\begin{array}{l}\text { Etkileşimde } \\
\text { Sorumluluk }\end{array}$} & $r$ &,$- 148^{* *}$ & 193** & , 132* & 1 \\
\hline & $\mathrm{p}$ &, 003 & 000 & ,009 & \\
\hline & $\mathrm{N}$ & 392 & 392 & 392 & 392 \\
\hline
\end{tabular}

${ }^{* *} \mathrm{p}<.001{ }^{*} \mathrm{p}<.005$

Faktörler arası çoklu korelasyon analizi sonuçlarına bakıldığında en güçlü ilişkinin etkileşimde hoşlanma ile kültürel farklılıklara saygı faktörleri arasında olduğu görülmektedir (r(392)=-.40, p<.001). İki faktör arasında ters yönde anlamlı bir ilişki vardır. Etkileşimden hoşlanma ve etkileşimde kendine güvenme faktörleri arasında da ters yönde anlamlı bir ilişki vardır $(r(392)=-.20, p<.001)$, etkileşimden hoşlanma ve etkileşimde sorumluluk faktörleri arasında da ters 
yönlü anlamlı bir ilişki vardır $(\mathrm{r}(392)=-14$, $\mathrm{p}<001)$. Bu faktörler arasında ters yönde bir ilişki olmasının nedeni ise "Etkileşimde Hoşlanma" faktörünü oluşturan maddelerin "olumsuz cümle" yapısında olmalarıdır.

Kültürel farklılıklara saygı ve etkileşimde kendine güvenme faktörü arasında aynı yönde anlamlı bir ilişki vardır (r(392)=,10, p<.005). Kültürel farklılıklara saygı ve etkileşimde sorumluluk faktörleri arasında aynı yönde anlamlı bir ilişki vardır ( $\mathrm{r}(392)=, 19, \mathrm{p}<.005)$. Etkileşimde kendine güvenme" ve etkileşimde sorumluluk" faktörleri arasında da aynı yönde anlamlı bir ilişki vardir $(\mathrm{r}(392)=, 13, \mathrm{p}<.005)$.

\section{Kültürlerarası İletişim Duyarlılık Düzeyi ve Cinsiyet Değişkeni Arasın- daki İlişki}

Bu başlık altında çalışmaya katılanların anket maddelerine verdikleri yanıtlar arasında cinsiyete göre anlamlı bir fark olup olmadığını belirlemek amacıyla yapılan Bağımsız Örneklem T-testi sonuçlarına yer verilmiştir. Bağımsız Örneklem T-testi yapılmadan önce faktörleri oluşturan maddelerin ortalaması alınmıştır.

Tablo 5. Kültülerarası İletişim Duyarlılık Düzeyi ve Cinsiyet Değişkeni Arasındaki İlişki

\begin{tabular}{lcllllll}
\hline Faktör & Cins. & $\mathbf{N}$ & Ort. & S.S. & S.D. & t & p \\
\hline Etkileşimden Hoşlanma & K. & 195 & 2,1067 &, 70114 & 390 & $-2,974$ &, 003 \\
& E. & 197 & 2,3330 &, 80238 & & & \\
\hline Kültürel Farklılıklara Sayg1 & K. & 195 & 4,3670 &, 58796 & 390 & 3,862 &, 000 \\
& E. & 197 & 4,0966 &, 78469 & & & \\
\hline Etkileşimde Kendine & K. & 195 & 3,4685 &, 71793 & 390 & $-1,378$ &, 169 \\
Güvenme & E. & 197 & 3,5730 &, 78195 & & & \\
\hline Etkileşimde Sorumluluk & K. & 195 & 3,7134 &, 62733 & 390 &,- 897 &, 370 \\
& E. & 197 & 3,7672 &, 55760 & & & \\
\hline
\end{tabular}

Elde edilen bulgulara göre katılımcların etkileşimden hoşlanma faktörüne ilişkin görüşleri arasında kadınlarla erkekler arasında anlamlı bir farklılık bulunmuştur $(\mathrm{t}(390)=2,974 ; \mathrm{p}<0,05)$. Erkeklerin etkileşimden hoşlanma faktörünü oluşturan maddelere ilişkin görüşlerinin ortalaması (Ort.=2,33; S.S.= .80), kadınların etkileşimden hoşlanma faktörünü oluşturan maddelere ilişkin görüşlerinin ortalamasından (Ort.=2,10; S.S.=.70) daha yüksektir. Bu sonuçlar erkeklerin kadınlara göre farklı kültürlerden bireylerle etkileşim halinde olmaktan daha çok hoşlandıklarını göstermektedir. 
Kadın ve erkek katılımcların kültürel farklılıklara saygı faktörüne ilişkin görüşleri arasında anlamlı bir farklılık vardır $\left(t_{(390)}=3,862 ; p<0,05\right)$. Kadınların kültürel farklılıklara sayg faktörünü oluşturan maddelere ilişkin görüşlerinin ortalaması(Ort. $=4,36 ; \quad$ S.S.=.58), erkeklerin görüşlerinin ortalamasından (Ort.=4,09; S.S.=78) yüksektir. Dolayısıyla kadınların farklı kültürlerden bireylerin kültürlerine daha çok saygı duyma eğiliminde olduklarını söylemek mümkündür.

Etkileşimde kendine güvenme faktörüne ilişkin kadın ve erkeklerin görüşleri arasında anlamlı bir fark olduğu görülmektedir $\left(\mathrm{t}_{(390)}=1,378 ; \mathrm{p}<0.05\right)$. Erkeklerin etkileşimde kendine güvenme faktörünü oluşturan maddelere ilişkin görüşlerinin ortalaması (Ort.=3,57; S.S.=.78), kadınların görüşlerinin ortalamasından (Ort.=3,46; S.S.=.71) yüksektir. Bu sonuçlar erkeklerin farklı kültürlerle etkileşim sırasında kadınlara göre kendilerine daha fazla güvendiklerini göstermektedir.

Etkileşimde sorumluluk faktörüne ilişkin de kadınlarla erkekler arasında anlamlı bir farklılık vardır $\left(\mathrm{t}_{(390)}=-897 ; \mathrm{p}<0.05\right)$. Bu faktörde de erkeklerin görüşlerinin ortalaması (Ort.=3,76; S.S.=.55), kadınların görüşlerinin ortalamasindan (Ort.=3,71; S.S.=.62) daha yüksektir. Dolayısıyla farklı kültürlerden bireylerle etkileşim sırasında sorumluluk almada erkeklerin kadınlara göre daha istekli olduklarını söylemek mümkündür.

\section{Sonuç}

20. yüzyıldan itibaren küresel bir bütün haline gelen dünyada yalnızca ülkeler arasındaki fiziksel sınırlar ortadan kalkmamış, kültür coğrafyaları da bir bütün haline gelmiştir. Artık kültürlerarası geçişsizlik/etkileşimsizlik söz konusu değildir. Ancak kültürlerin karşılaşmasında yaşanması muhtemel birtakım farklılıklar vardır. Söz konusu bu farklılıkların bireyler tarafından ön yargısız ve saygıyla karşılanması önemlidir. Bir bireyin bir kültüre adapte olabilmesi de onun kültürlerarası iletişim yeteneği ile doğru orantılıdır. Kültürlerarası iletişim yeteneği üç aşamada gerçekleşmektedir ve bu aşamaların ilki kültürlerarası duyarlılığın gelişmesidir. Her bir aşamaya geçiş bir önceki aşamanın tamamlanmasına bağlıdır. Dolayısıyla kültürlerarası duyarlılık gelişmeden diğer aşamalara geçmek mümkün değildir.

Niğde Ömer Halisdemir Üniversitesi öğrencilerinin kültürlerarası duyarlılık düzeylerinin belirlenmesinin amaçlandığı bu çalışmada 392 öğrenciye "Kültürlerarası Duyarlılık Ölçeği" uygulanmıştır. Öğrencilere demografik 
özellikler açısından cinsiyet ve uyrukları sorulmuş, yapılan Frekans Analizi sonucunda cinsiyet değişkeni bağlamında katılımcıların normal bir dağılım gösterdiği görülmüştür.

Çalışmada Chen ve Starosta'nın "Kültürlerarası Duyarlılık Ölçeği” kullanılmıştır. Ancak ölçek çeviri oluğundan ve yeni bir örneklem grubuna yapılacağından doğrulayıcı değil keşfedici faktör analizi yapılmış ve çalışmanın örneklemi bazında 12 maddelik 4 faktör ortaya çıkmıştır. Bu faktörler; "Etkileşimden Hoşlanma", "Kültürel Farklılıklara Saygı", "Etkileşimde Kendine Güvenme" ve "Etkileşimde Sorumluluk" olarak isimlendirilmiştir ve faktörlerin ortalaması alınmıştır. Faktörler arasındaki ilişkinin yönünü ve düzeyini belirlemek amacıyla yapılan korelasyon analizinde en güçlü ilişkinin "Etkileşimden Hoşlanma" ve "Kültürel Farklılıklara Saygı" faktörleri arasında olduğu sonucuna varılmıştır. Bununla birlikte tüm faktörler arasında anlamlı ilişki olduğu görülmüştür.

Cinsiyet değişkeni bağlamında faktörleri oluşturan maddelere ilişkin katılımcıların görüşleri arasında anlamlı bir fark olup olmadığını belirlemek amacıyla Bağımsız Örneklem T-Testi yapılmıştır. Tüm faktörlerde kadınlarla erkekler arasında anlamlı bir fark olduğu, kültürel farklılıklara saygı konusunda kadınların erkeklerden daha duyarlı oldukları, ancak farklı kültürlerle etkileşimden hoşlanma, etkileşim sırasında kendine güvenme ve sorumluluk alma konusunda erkeklerin kadınlara göre daha duyarlı oldukları sonucuna varılmıştır.

Çalışmanın sonuçları değerlendirildiğinde Tamam (2010) ile Bekiroğlu ve Balcı'nın (2014) çalışmalarında olduğu gibi Chen ve Starosta'nın beş fakötürünün tümüyle yinelenmediği görülmüştür. Özellikle Bekiroğlu ve Balcı'nın ulaştığ 1 "Etkileşimde Sorumluluk/Dikkatli Olma”, "Etkileşimde Knedine Güvenme", "Kültürel Farklara Saygı", "Etkileşimden Hoşlanma" faktörlerine giren maddeler ile bu çalışmanın sonuçları benzerlik göstermektedir. Bu çalışmada da ölçek maddelerinin Bekiroğlu ve Balcı'nın çalışmalarındaki aynı farktörler altında toplandığı sonucuna varılmıştır.

Chen ve Starosta'nın ölçeğinin kullanıldığı bu çalışmada ölçekte yer alan beş faktör yinelenmemiş, dört faktör grubu ortaya çıkmıştır. Bu çalışma göstermiştir ki ilgili envanter farklı kültürel bağlamlarda uygulandığında farklı sonuçlara ulaşmak mümkündür. Bununla birlikte farklı uyruklardan katılımcıların normal dağılım göstereceği bir çalışmada da farklı sonuçlara ulaşılabilir, bu nedenle bu yönde de çalışmalar yapılabilir. 


\title{
EXTENDED ABSTRACT
}

\section{A Research on Intercultural Sensitivity of Nigde Ömer Halisdemir University Students}

\author{
Duygu Ünalan \\ Niğde Ömer Halisdemir University
}

In the 20th century, humanity have showed a marked improvement in terms of scientific and technological developments which haven't seen in previous centuries. Imperialism have unified the world global integration, asymmetric relations have started between states and cultures, economic relations based on interchange and mutual dependence have became widepsread. Although this dominance relationship has produced negative results, it has also provided an environment for contacting which enables meeting of differences on the conditions in which there are equality and distinctness. (Kartarl, 2014, p.26-27). So human communities, which formed an interaction with immediate environment for centuries, has began cross border communication because of globalisation.

Starting with suzerain's expeditions to near countries and continents in 1490 with the thought that mercantalisim and developing in 1990's, the fact of globalisation has caused alteration economic, political, sociocultural and technological areas in the World (Saran, 2013, p.443). Social and economic developments, globalisation and internationalisation increased the significance of communication competence of individuals from different cultures. Therefore, individuals began to need intercultural sensitivity when they encounter different cultures. Globalisation, internationalisation, developments, developments in communication increased the opportunity of intercultural communication and interaction. When the developments, which provide more opportunities to individuals for intercultural communication and interaction, are considered intercultural sensitivity took a big role as a social and communicational industry (as cited in Fritz vd. 1999, Fritz vd.,2002, p.165; Tamam, 2010: , p.174).

In cultural antropological and intercultural physcology, culture means collective life experiements of recognizable big groups such as a nation or a 
world area. Over the years, this concept has enlarged including gender, physical ability or disability, subcultures of local ethnic or racial groups in geographical areas. The point issue of inter cultural communication is to focus on communication and interaction between individuals from different cultures and subcultures (Kim, 2005, p.555-556).

Throughout the human history, individuals have traveled to find better living space, to trade or promulgate religion being in the first place and other thoughts. When they have gone to different places, they have encountered individuals who have grown up in different living conditions; in other words, from different cultures. Through developments in communication and transportation technologies, with Mc Luhan's words the world became 'a global village'. Especially developments in the last fifty years have caused the World has been getting smaller, so any nation or culture have become unviable while finishing relations with others. New technological and communication systems, world population increase, changing of world economic centers, increasing socio cultural and economic migrations have intensified communication between different cultures. (Kartar1, 2001, p.9). All these developments have increased the significance of inter cultural communication competence and inter cultural sensitivity which is complementary and intensifier of inter cultural communication, and have become inter cultural sensitivity indispensable (Bekiroğlu and Balcı, 2014, p.433).

Developing of inter cultural communication competence, recognizing cultural differences respect and show tolerance for them enables that effectual communicate in different cultural environments. Development of the competence in point realizes in three phases and the first phase is inter cultural sensitivity component. The second phase is inter cultural awareness, the third phase is inter cultural proficiency. These phrases alternate and if the previous phrase do not complete, the next phrase will not start (Kartarı, 2001, p.211). Therefore, development of inter cultural sensitivity is a prior condition for other phrases.

In this study, Chen and Starosta's inter cultural sensitivity conceptualization is grounded on. According to Chen and Starosta (1997, p.5), inter cultural sensitivity deals with cognitive, emotional and behavioral sides of interaction; at the same time, elementarily deals with the emotional side. In addition to this, inter cultural awareness which is corresponding to cognitive level is the foundation of inter cultural sensitivity which is corresponding to emotional 
level and both of them carry inter cultural competence in regular turn. Intercultural Sensitivity Scale, developed by Chen and Starosta has been planned as 73 items in the first phase and has been used 5 point Likert scale for each item (Chen and Starosta, 2000, p.5). These items have been planned according to six properties which authors think that individuals should have in intercultural sensitivity scale. These are self-esteem, self-monitoring, unorthodoxy, empathy and unprejudicedness. Based on these concepts, it is possible to say that individuals who have high level of intercultural sensitivity level should be individuals who cope with alienation in intercultural communication, disappoinment and stress; who have an ability to change his/her behaviours when there is conflict and to adapt different communication conditions, who are open to different thoughts, can make empathy and free from prejudices (Chen and Starosta, 1997, p.7-10).

Chen and Starosta (2000, p.5-8) reduced the scale to 44 items through factor analysis as a result of the first study which they did with 168 first class students in Communication Faculty. On the other hand, in the second study, they aimed to test Intercultural Sensitivity Scale's simultaneous validity with related scales and at the end of the study, they designed scale again as 24 items. These 24 items are 5 factors's declination related to intercultural sensitivity: These are responsibility in interaction, respect to cultural differences, trust yourself in interaction, and being careful in interaction.

In this study, the question that Niğde Ömer Halisdemir University's students' level of intercultural sensitivity has been searched for an answer. The aim of this study is to reveal Niğde Ömer Halisdemir University's students' intercultural sensitivity level. In this study, intercultural sensitivity scale has been applied to 392 students. The survey was conducted between 1-30 April 2018. The data were digitized using SPSS 24.0 statistical program. In the analysis of the data; Frequency analysis to determine the demographic characteristics of the respondents; Exploratory Factor Analysis was conducted to reveal the factors of intercultural communication sensitivity level. Correlation Analysis was used to determine the relationship between intercultural communication sensitivity level factors and Independent Sample T-test was used to determine the relationship between intercultural communication sensitivity level and gender. When the demographic characteristics of the participants were analyzed, a total of 195 women and 197 men answered the questionnaire. 158 of the women are Turkish and 37 are foreign. Of the males, 148 
are Turkish and 49 are foreign nationals. Therefore, a total of 306 Turkish and 86 foreign students participated in the survey.

Firstly, in order to determine the structural validity of the scale, Exploratory Factor Analysis was applied by using principal component analysis and varimax quadruple technique. As a result of KFA, the sample adequacy value of Kaiser-Meyer-Olkin (KMO) was found to be 0.84 and the sample size was sufficient for factor analysis. The significance of Bartlett's sphericity test [ $\mathrm{x} 2$ $(276)=2358,064 \mathrm{p}<0.05]$ indicates that the correlation between items is appropriate for factor analysis. As a result of the EFA analysis, firstly, a six-factor result was obtained. As a result of the first factor analysis, twelve items showed a tendency to cross-load, so these items were excluded from the scale. As a result of the reconstructed EFA, the 12-item scale had a four factors structure. These factors are; "Enjoyment of Interaction", "Respect for Cultural Differences", “Confidence in Interaction" and "Responsibility in interaction". Independent Sample T-Test was used to determine whether there was a significant difference between the opinions of the participants about the items constituting the factors in the context of gender variable. It was concluded that there was a significant difference between men and women in all factors, and that women were more sensitive than men to respect cultural differences, but men were more sensitive than women to enjoy interacting with different cultures, taking confidence and taking responsibility during interaction.

\section{Kaynakça / References}

Awang-Rozaimie, A.S., Amelia, A.T., Aiza, J., Siti-Huzaimah, S. ve Adib, S. (2013). Intercultural sensitivity and cross-cultural adjustment among Malaysian students abroad. Journal of Educational and Social Research, 3(7), 693-703.

Bekiroğlu, O. ve Balcı, Ş. (2014). Kültürlerarası iletişim duyarlılığının izlerini arama: iletişim fakültesi öğrencileri örneğinde bir araştırma. Türkiyat Araştırmaları Dergisi, 25, 429-459.

Bennett, M. (1998). Intercultural communication: A current perspective. Basic concepts of intercultural communication. (Ed. M. Bennett). London: Intercultural Press, 1-34.

Bhawuk, D.P.S and Brislin, R. (1992). The measurement of intercultural sensitivity using the concepts of individualism and collectivism. International Journal of Intercultural Relations, 16, 413-436. 
Bulduk, S., Tosun, H. ve Ardıç, E. (2010). Türkçe kültürlerarası duyarlılık ölçeğinin hemşirelik öğrencilerinde ölçümsel özellikleri. Turkiye Klinikler J Med Ethics,19(1), 25-31.

Chen, G.M. ave Starosta, W. J. (1997). A rewiev of the concept of the intercultural sevsitivity. Human Communication, 1,1-16.

Chen, G. M. ve Starosta, W. J. (2000). The development and validation of the intercultural sensitivty scale. Human Communication, 3, 1-15.

Fritz, W., Graf, A., Hentze, J., ve Möllenberg, A. (2005). An examination of Chen and Starosta's model of intercultural sensitivty in Germany and United States. Intercultural Communication Studies, 14(1), 53-65.

Fritz, W, Möllenberg, A. ve Chen, G.M. (2002). Measuring intercultura sensitivty in different cultural contexts. Intercultural Communication Studies, 11(2), 165-176.

Hammer, M.R., Bennett, M.J. ve Wiseman, R. (2003). Measuring intercultural sensitivity: the intercultural development inventory. International Journal of Intercultural Relations, 27, 421-443.

Haviland, W.A., Prıns, H.E.L., Walrath, D. ve McBride, B. (2008). Kültürel antropoloji. İstanbul: Kaknüs Yayınları.

Jant, E. F. (2004).An introduction to intercultural communication.London: Sage Publications.

Kartarı, A. (2001). Farklliklarla yaşamak. Ankara: Ürün Yayınları.

Kartarı, A. (2014). Kültüur, farkllık ve iletişim. İstanbul: İletişim yayınları.

Kim, Y.Y. (2005). Inquiry in intercultural and development communication. Journal of Communication, 55(3), 554-577.

Oskay, Ü. (2007). İletişimin a b c'si. İstanbul: Der Yayınları

Penbek, Ş., YurdakuL, D. ve Cerıt, A. G. (2009). Intercultural communication competence: a study about the interculturalsSensitivity of university students based on their education and international experiences. A Paper Presented European and Mediterranean Conference on Information Systems 2009 (EMCIS2009), July 13-14 2009, Crowne Plaza Hotel, İzmir.

Saran, M. (2013). Küreselleşme ve kültür: sınırların belirleyicisi kültür. Küreselleşme ve Kültürlerarası İletişim, 40-70.

Tamam, E. (2010). Examining Chen and Starosta's model of intercultural sensitivity in a multiracial collectivistic country. Journal of Intercultural Communication Research. 39 (3), 173-173. 


\section{Kaynakça Bilgisi / Citation Information}

Ünalan, D. (2020). Niğde Ömer Halisdemir üniversitesi öğrencilerinin kültürlararası duyarlılıkları üzerine bir araştırma. OPUS-Uluslararası Toplum Araştırmaları Dergisi, 15(24), 2697-2719. DOI: 10.26466/opus.643764 